\title{
Antibiotic prophylaxis in low risk patients undergoing laparoscopic cholecystectomy
}

S. Kumar ${ }^{1}$, P.J. Lakhey ${ }^{2}$, P. Vaidya ${ }^{3}$, B.N. Patowary ${ }^{4}$, C.R Praveen ${ }^{1}$, P Shrestha $^{5}$

${ }^{1}$ Lecturer, ${ }^{4}$ Professor and Head, ${ }^{5}$ Resident, Department of General Surgery, CMS-TH, Chitwan, Nepal

${ }^{2}$ MCh Resident, ${ }^{3}$ Professor and Head, Department of General Surgery, TUTH, Maharajgunj, Kathmandu, Nepal

\begin{abstract}
Laparoscopic cholecystectomy is the 'gold standard' for benign diseases of gallbladder. It has rapidly gained popularity and it is one of the commonly performed operations in Nepal. The need for antibiotic prophylaxis when performing an elective laparoscopic cholecystectomy may not be as important as it is thought in low risk group. Despite, low postoperative infection rate in laparoscopic cholecystectomy in low risk group, the same criteria of antibiotic prophylaxis previously applied to conventional surgery are routinely used for laparoscopic surgery, even though its actual need has not been ascertained. Aim of this study was to assess the efficacy of antibiotic prophylaxis in elective laparoscopic cholecystectomy with respect to postoperative Surgical Site Infection (SSI) in low risk group. Study was carried out in The Department of Surgery, Tribhuvan University Teaching Hospital, Kathmandu, Nepal from May 2005 to June 2006 (14 months).This was a prospective randomized study done on 104 consecutive patients undergoing laparoscopic cholecystectomy. Patients were randomized into case group (group A) and control group (group B) with 52 patients in each group. Two and four patients from Group A and Group B respectively were excluded. In Group A, 50 patients received one gram ceftriaxone intravenously 30 minutes prior to induction of anesthesia and in Group B, all 48 patients received 10 milliliters (ml) of isotonic sodium chloride solution intravenously 30 minutes before induction. In both groups, age, sex, ultrasonogram findings, duration of surgery, American society of anesthesiologists patient classification score, antibiotic administration, bile spillage during surgery, length of postoperative hospital stay and postoperative SSI were recorded. Patients were advised to follow up in Surgical Out-patient Clinic if there was any evidence of SSI within 30 days. SSI was reported and classified as, superficial incisional, deep incisional or space / organ SSI. There were a total of 98 patients included in the study; 50 in Group A and 48 in Group B. In group A, three (6\%) patients and in Group B, also three (6.3\%) patients had superficial incisional SSI. None of them had deep or organ / space SSI. Comparison of data showed no statistically significant difference between two groups (P-1.00).
\end{abstract}

Key words: Antibiotic prophylaxis, laproscopic cholecystectomy, surgical site infection.

\section{Introduction}

Surgical antibiotic prophylaxis is defined as the use of antibiotics to prevent infections at the

Correspondence: S. Kumar

E-mail: drsujit1755@yahoo.com surgical site. Antibiotic prophylaxis which was introduced in 1960, has been shown to markedly decrease the incidence of septic complications in biliary surgery with the published rate ranging from $0 \%$ to $4 \% .{ }^{1}$ It should be given at the correct time. 
S. Kumar et al. Antibiotic prophylaxis in low risk patients undergoing laparoscopic cholecystectomy

The first dose should always be given before the procedure, preferably within 30 minutes before incision. Readministration depends on half-lives of the antibiotic and duration of the procedure. ${ }^{2,3}$ In general, postoperative administration is not recommended. Antibiotic selection is influenced by the organism most commonly causing wound infection in the specific procedure., ${ }^{4,5}$

Elective laparoscopic cholecystectomy has a low risk for infection but many surgeons still use prophylactic antibiotics. Meta-analysis suggests wound infection rate of $2.2 \%$ in low-risk patients undergoing laparoscopic cholecystectomy without prophylactic antibiotics and $1.5 \%$ with prophylactic antibiotic. ${ }^{6,7,8}$ This study was designed to asses the infection rate in patients undergoing elective laparoscopic cholecystectomy.

Patients, who do not have any signs and symptoms suggestive of acute cholecystitis within 30 days, do not have history of cholangitis, obstructive jaundice, previous biliary tract surgery, diabetes mellitus and patients with ASA 1 and 2 are considered to be in low risk group. Meta- analysis suggests antibiotic prophylaxis is not warranted in low-risk patients undergoing laparoscopic cholecystectomy.

\section{Objectives of study}

- To assess the SSI in laparoscopic cholecystectomy in low risk group with prophylactic antibiotics.

- To assess the SSI in laparoscopic cholecystectomy in low risk group without prophylactic antibiotics.
- Comparison of SSI in laparoscopic cholecystectomy in low risk group with and with out prophylactic antibiotics.

\section{Materials and methods}

\section{Patients}

A prospective randomized study carried out from May 2005 to June 2006 in Department of Surgery, Tribhuvan University Teaching Hospital, Kathmandu, Nepal for a period of 14 months done on 104 consecutive patients undergoing laparoscopic cholecystectomy. Patients were randomized into case group (group A) and control group (group B). Odd number patients were included in group $A$ and even number patients were included in group B. Two patients from group A and four patients from group B were excluded from study. In both groups, age, sex, duration of surgery, American society of anesthesiologists patient classification score, antibiotic administration, bile spillage during surgery, length of postoperative hospital stay and postoperative SSI were recorded. All patients were examined by attending surgeons and follow up was done $5^{\text {th }}-7^{\text {th }}$ and $14^{\text {th }}$ postoperative days in Surgical Out-patient Clinic with histopathological examination (HPE). Patients were advised to follow up in Surgical Out-patient Clinic if there was any evidence of SSI within $30^{\text {th }}$ post operative day. SSI was reported and classified as, superficial incisional, deep incisional or space / organ SSI.

\section{Methods}

Approval for the study was obtained from Department of Surgery, Tribhuvan University Teaching Hospital and informed consent was 
obtained from all patients. Patient fulfilling the selection criteria were included in the study. Preoperative thorough history, physical examination and investigations were reviewed and a proforma was filled before induction of anesthesia, patients were randomized prospectively into one of two groups, A or B. Group A, received one gram ceftriaxone intravenously, 30 minutes before induction and group B, received $10 \mathrm{ml}$ normal saline 30 minutes before induction. All the procedures were performed under general anesthesia.

Laparoscopic cholecystectomy in this study was started with an open technique of trocar insertion through the sub-umbilical port and the creation of $\mathrm{CO}_{2}$ pneumoperitoneum to the pressure of 10 to $15 \mathrm{~mm}$ of $\mathrm{Hg}$ with a flow rate of 3-5 liters per minute. Under laparoscopic view, further two or according to the European four puncture technique ${ }^{4}$, three ports were made. After dissection of cystic duct and cystic artery, three or four metallic clips were applied on each and the cystic duct and artery were divided distal to the proximal two clips. Monopolar diathermy in a coagulation mode was used for the dissection of the gallbladder from the liver bed. The gallbladder was removed through the periumbilical port. Gallbladder fossa and periportal area was washed with normal saline and all the irrigant fluid was sucked out as required. Negative pressure (suction) drain was kept at the gallbladder fossa at the discretion of operating surgeon. Pneumoperitoneum was then evacuated and port sites were closed with umbilical port in two layers, fascial and skin, while the other ports are being closed in one layer of skin only after infiltration with $0.5 \%$ bupivacaine in all cases. The light sources, telescopes and laparoinflator were from Karl Storz and Olympus.

The intra operative parameters recorded were the duration of surgery, number of ports used, bile spillage and operative findings. Patients were discharged when they were able to ambulate and care for themselves usually on $2^{\text {nd }}$ or $3^{\text {rd }}$ postoperative day. After discharge; patients were followed up in Surgical Out-patient Clinic on $5^{\text {th }}$ $7^{\text {th }}$ Postoperative day and on $14^{\text {th }}$ day with HPE report. Suture was removed on $7^{\text {th }}$ postoperative day. Those patients who developed SSI, pus from site was sent for culture sensitivity; oral antibiotic cefadroxil (500 mg twice daily) was started before its report with daily dressing. After getting culture report antibiotic was given accordingly for 7 days. We gave Cefadroxil because of its good tissue penetration and local action.

\section{Inclusion criteria}

All patients aged between 18-70 years undergoing elective laparoscopic cholecystectomy during the study period.

\section{Exclusion criteria}

Patients younger than 18 years and older than 70 years. Pregnant or lactating women. Patients allergic to antibiotics. Antibiotic therapy within 48 hours prior to surgery. Evidence of acute cholecystitis in 30 days, cholangitis or obstructive jaundice and Previous biliary tract surgery. History of prosthetic valves or joints. History of diabetes mellitus. Laparoscopic cholecystectomy converted to open cholecystectomy. Empyema of gall bladder per operative findings. 


\section{S. Kumar et al. Antibiotic prophylaxis in low risk patients undergoing laparoscopic cholecystectomy}

\section{Statistical analysis}

In this study we used $\mathrm{Z}$ test, Fisher's exact test and Chi square test for testing significance of the study. Computer program SPSS 11.5 was used for data collection and analysis and $\mathrm{p}$ value $<0.05$ was considered statistically significant.

\section{Results}

A total of 104 patients were included in the study and randomized into two groups; case (Group A) and control (Group B) with 52 patients in each group. Two patients from group A were excluded as they were converted into open Cholecystectomy and from Group B, four patients were excluded (three were converted to open Cholecystectomy; and in one patient, operative finding was empyema of gall bladder for which antibiotic was continued after operation for seven days). Thus, 50 patients from Group A and 48 from Group B fulfilled the criteria for study and were included. All underwent laparoscopic cholecystectomy in Tribhuvan University Teaching Hospital (TUTH) during the study period.

The female to male ratio was $2.57: 1(36: 14)$ in Group A and 1.82:1(31:17) in Group B. Thus, females were dominating in both groups, constituting $72 \%$ and $64.6 \%$ in Group A and Group $\mathrm{B}$ respectively. The mean age (range) was 35.2 (19$65) \pm 11.6 y e a r s$ in Group A and $36.0(18-67) \pm 12.00$ years in Group B.

All 98 patients included in study were symptomatic. Most common symptoms in both groups were biliary colic, right upper quadrant pain, dyspepsia and fat intolerance. None of them had signs and symptoms of acute cholecystitis during admission. Duration of symptoms was 3 months to 42 months in Group A with mean of 16.24 9.61 (SD) months. In Group B, symptoms were present for 4 to 48 months with the mean of $18.68 \pm 10.44$ (SD) months ( $p>0.05)$. Thus, the duration of symptoms varied from 3 to 48 months in this study. All patients were subjected to an abdominal USG as a part of preoperative evaluation. USG revealed multiple stones in $33(66 \%)$ and solitary stones in $17(34 \%)$ in group A patients and in Group B, 36 (75.0\%) patients had multiple stones and 12 (25.0\%) had solitary stones. Most of the patients in both groups (Group A, 45 patients and in group B, 46 patients) had ASA score 1.Only four patients in Group A and three patients in Group B had ASA score 2.

In both groups, three ports were used more frequently. Three ports were used in 37 patients (74\%) and in 38 patients (79.2\%) in Group A and Group B respectively; where as four ports were used in 13 patients and 10 patients in Group A and Group $\mathrm{B}$ respectively. Among 50 patients in Group A, six had bile spillage where as in Group B, five patients had bile spillage during operation. Five patients from each group had postoperative closed romovac drain in right sub hepatic space, which was taken out on $2^{\text {nd }}$ postoperative day before discharge(Table $1)$. The mean duration of hospital stay in both groups was 2.5 days \pm 0.5 . The mean gas used was 94 liters \pm 21.7 in the Group A and 95.6 liters \pm 23.8 in the Group B. The mean duration of operation was 49.3 minutes \pm 12.7 in the Group A and 54.5 minutes \pm 20.7 in the Group B . Thus both groups were similar in regards to age, sex, type of stones, symptomatology, duration of 
symptoms, laboratory investigations, ASA grading, number of ports used, duration of operation, and postoperative hospital stay.

In group A, three (6\%) patients and in Group B, also three $(6.3 \%)$ patients had superficial incisional SSI. None of them had deep or organ / space SSI. $(\mathrm{P}=1.00)$, which is statistically not significant (Table 2). Two patients from each group had wound infection on $5^{\text {th }}$ day and one from each group had wound infection on $6^{\text {th }}$ day (Table 3$)$. Oral antibiotic Cefadroxil $500 \mathrm{mg}$ twice daily was started with daily dressing in all these patients. Pus culture was obtained from all the patients. Only two patients, one from each group had growth in it, rest of four patients had no growth. One patient in Group A, had E coli in growth sensitive to ciprofloxacin who was treated accordingly (Table4). Another patient in Group B, had staphylococcus aureus sensitive to Cefadroxil and Cloxacillin, he was getting Cefadroxil before obtaining report, and same medicine was continued for him. All patients were cured by $11^{\text {th }}$ postoperative day. None of them reported with SSI till $30^{\text {th }}$ postoperative day.

\section{Discussion}

Incidence of SSI after laparoscopic cholecystectomy in low risk group has been varying from $1.5 \%$ to $9.09 \%$ with prophylactic antibiotic in different studies. It is $2.2 \%$ to $12.5 \%$ without antibiotic prophylaxis. In most of studies incidence of SSI varies from $2 \%$ to $6 \%$ with or without antibiotic prophylaxis. Thus, in all studies (Table 5) there is no statistically significant difference of SSI after laparoscopic cholecystectomy in low risk group with or without prophylactic antibiotics. In this study incidence of SSI was 6\% in Group A and $6.3 \%$ in Group B which is statistically not significant. Therefore result of this study was similar to other studies.

Table 1: Ports used, bile spillage, peroperative drain and hospital Stay of patients

\begin{tabular}{lccc}
\hline \multicolumn{1}{c}{ Variables } & A & B & p value \\
& $(\mathrm{n}=50)$ & $(\mathrm{n}=48)$ & \\
\hline Ports used: & & & \\
Three & 37 & 38 & 0.55 \\
Four & 13 & 20 & \\
Bile spillage & & & \\
No & 44 & 43 & 0.80 \\
Yes & 6 & 5 & \\
Drain post operative & & & \\
No & 45 & 43 & 0.95 \\
Yes & 5 & 5 & \\
Hospital stay (days) & & & \\
2 & 28 & 26 & 0.98 \\
3 & 21 & 21 & \\
4 & 1 & 1 & \\
\hline
\end{tabular}


S. Kumar et al. Antibiotic prophylaxis in low risk patients undergoing laparoscopic cholecystectomy

Table 2: SSI in patients

\begin{tabular}{lccc}
\hline \multicolumn{1}{c}{ Variables } & A & B & p value \\
& $(\mathrm{n}=50)$ & $(\mathrm{n}=48)$ & \\
\hline Superficial & & & \\
Yes & $3(6 \%)$ & $3(6.3 \%)$ & \\
No & 47 & 45 & 1.00 \\
Deep & & & \\
Yes & 0 & 0 & \\
No & 50 & 48 & \\
Organ/Space & & & \\
Yes & 0 & 0 & \\
No & 50 & 48 & \\
\hline
\end{tabular}

Table 3: SSI on postoperative day

\begin{tabular}{lccc}
\hline \multicolumn{3}{c}{ Group } & \\
\multicolumn{1}{c}{ Superficials SSI } & A & B & p value \\
\hline $5^{\text {th }}$ Day & 2 & 2 & \\
$6^{\text {th }}$ Day & 1 & 1 & 1.00 \\
Total & $\mathbf{3}$ & $\mathbf{3}$ & \\
\hline
\end{tabular}

Table 4: Pus culture and sensitivity in patients

\begin{tabular}{lccc}
\hline $\begin{array}{c}\text { Pus Culture and } \\
\text { Sensitivity }\end{array}$ & A & B & p value \\
\hline Growth & 1 & 1 & \\
Organism & E-coli & Staphylococus & 1.00
\end{tabular}
aureus

Sensitivity Ciprofloxacin Cefadroxil

\begin{tabular}{lll} 
No Growth & 2 & 2 \\
\hline Total & 3 & 3
\end{tabular}

Table 5: Studies comparing prophylactic antibiotics verses placebo to see postoperative SSI in laparoscopic cholecystectomy in low risk group

\begin{tabular}{|c|c|c|c|c|c|c|}
\hline Author & $\begin{array}{c}\text { Journal } \\
\text { Year,volume, page }\end{array}$ & $\begin{array}{c}\text { No.of } \\
\text { patients } \\
\text { in case } \\
\text { group }\end{array}$ & $\begin{array}{c}\text { No. of } \\
\text { patients in } \\
\text { control } \\
\text { group }\end{array}$ & $\begin{array}{l}\text { SSI with } \\
\text { prophylactic } \\
\text { antibiotics }\end{array}$ & $\begin{array}{l}\text { SSI with out } \\
\text { antibiotic } \\
\text { prophylaxis }\end{array}$ & $\begin{array}{c}\mathrm{p} \\
\text { value }\end{array}$ \\
\hline $\begin{array}{l}\text { R. AL-Ghnaniem et } \\
\text { al: }\end{array}$ & BJS 2003;90:536-544 & 528 & 371 & $\begin{array}{c}8 \\
(1.5 \%)\end{array}$ & $\begin{array}{c}8 \\
(2.2 \%)\end{array}$ & 0.50 \\
\hline $\begin{array}{l}\text { Mahatharadol V et } \\
\text { al: }\end{array}$ & $\begin{array}{l}\text { Med Assoc Thai 2001; } \\
84: 105-108\end{array}$ & 64 & 64 & $\begin{array}{c}4 \\
(6.2 \%) \\
4\end{array}$ & $\begin{array}{c}4 \\
(6.2 \%) \\
5\end{array}$ & 1.00 \\
\hline $\begin{array}{l}\text { Adriano Tocchi, MD } \\
\text { et al: } \\
\text { Andrew Higgins, }\end{array}$ & $\begin{array}{l}\text { Arch Surg 2000;135: } \\
\text { 67-70. } \\
\text { Arch Surg 1999;134: }\end{array}$ & 44 & 40 & $\begin{array}{c}4 \\
(9.09 \%) \\
3\end{array}$ & $\begin{array}{c}5 \\
(12.5 \%) \\
3\end{array}$ & 0.91 \\
\hline MD et al: & $\begin{array}{l}\text { 611-614 } \\
\text { Am Surg }\end{array}$ & 150 & 150 & $\begin{array}{c}(2 \%) \\
3\end{array}$ & $\begin{array}{l}(2) \\
4\end{array}$ & 1.00 \\
\hline Dobay KJ et al: & $\begin{array}{l}\text { 1999;65: } \\
226-228\end{array}$ & 55 & 52 & $(5.4 \%)$ & $(7.6 \%)$ & 0.94 \\
\hline LLig KA et al: & $\begin{array}{l}\text { J Am Coll Surg 1997; } \\
\text { 184:353-356 } \\
\text { Eur J Surg }\end{array}$ & 48 & 44 & $\begin{array}{l}3 \\
(6.25 \%) \\
2\end{array}$ & $\begin{array}{c}4 \\
(9.09 \%) \\
3\end{array}$ & 0.90 \\
\hline Watkin DS et al: & $\begin{array}{l}\text { 1995;161: } \\
509-511\end{array}$ & 88 & 84 & $(2.2 \%)$ & $(3.5 \%)$ & 0.90 \\
\hline Frantzides CT et al: & $\begin{array}{l}\text { J Laparo } \\
\text { endoscope Surg 1994; } \\
\text { 4:375-378 }\end{array}$ & 108 & 106 & $\begin{array}{l}4 \\
(3.70 \%)\end{array}$ & $\begin{array}{c}4 \\
(3.77 \%)\end{array}$ & 1.0 \\
\hline This study & September 2006 & 50 & 48 & $\begin{array}{c}3 \\
(6 \%)\end{array}$ & $\begin{array}{c}3 \\
(6.3 \%)\end{array}$ & 1.0 \\
\hline
\end{tabular}




\section{Conclusion}

This study showed that use of prophylactic antibiotics in elective laparoscopic cholecystectomy would not decrease the SSI in low risk group, so antibiotic prophylaxis is not warranted in low risk patients undergoing laparoscopic cholecystectomy.

\section{References}

1. J. Simo, P. Matis, S. Durdik, et al. Antibiotic prophylaxis in surgery. Bratisl Lek Listy 1999; 100(12): 694-7.

2. W.J. Gillespie, G. Walenkamp. Antibiotic prophylaxis for surgery for proximal femoral and other closed long bone fracture. Cochrane Database Syst Rev 2000; (2): 244.

3. H. Hayashi, Y. Yaginuma, T. Yamashita et al. Prospective randomized study of antibiotic prophylaxis for non laparotomy surgery in benign conditions. Chemotherapy 2000; 46(3): 213-8.

4. D.S. Watkin, A.M. Wainwright, M.H. Thompson et al. Infection after laparoscopic cholecystectomy:are antibiotics really necessary? Eur J Surg 1995; 161: 509-11.
5. N. Garcia, S. Kapur, J. McClane et al. Surgical infections and prophylactic antibiotics: 341 consecutive cases of gallbladder surgery in the era of laparoscopic surgery. J Laparoendosc Adv Surg Tech 1997; 7: 157-62.

6. R AL - Ghnaniem, I.S. Benjamin, A. G. patel. Meta analysis suggests antibiotic Prophylaxis is not warranted in low- risk patients undergoing laparoscopic cholecystectomy. British journal of surgery 2003; 90: 365-6.

7. K.A. Lllig, E. Schmidt, J. Cavanaugh, et al. Are prophylactic antibiotic required for elective laparoscopic cholecystectomy ? J Am Coll Surg. 1997; 184: 353-6.

8. C.T. Frantzides, A. Sykes. A reevaluation of antibiotic prophylaxis in laparoscopic cholecystectomy. $J$ Laparoendosc Surg 1994; 4: 375-8.

9. A. Higgins, J. London Antibiotic prophylaxis in elective laparoscopic cholecystectomy. Arch Surg. 1999; 134 :611-3. 